\title{
Does message framing matter for promoting the use of nutritional warnings in decision making?
}

\author{
Gabriela Vidal', Leandro Machín', Jessica Aschemann-Witzel2 and Gastón Ares 1,3,* \\ 'Centro de Investigación Básica en Psicología, Facultad de Psicología, Universidad de la República, Tristán Narvaja \\ 1674, CP 1 1200, Montevideo, Uruguay: ${ }^{2}$ MAPP Centre for Research on Customer Relations in the Food Sector, \\ Aarhus University, Aarhus, Denmark: ${ }^{3}$ Sensometrics \& Consumer Science, Instituto Polo Tecnológico de Pando, \\ Facultad de Química, Universidad de la República, By Pass de Rutas 8 y 101 s/n, CP 91000 , Pando, Canelones, \\ Uruguay
}

Submitted 27 January 2019: Final revision received 26 May 2019: Accepted 3 June 2019; First published online 29 August 2019

\begin{abstract}
Objective: To evaluate the impact of message framing on attitudes towards messages aimed at promoting the use of nutritional warnings, behavioural intention and actual behaviour, evaluated through visual attention to nutritional warnings and the choice of a snack product during a real choice task.

Design: Following a between-subjects design, participants were exposed to lossframed nutrition messages, gain-framed nutrition messages or non-nutritionrelated messages (control group). After evaluating the messages, participants were asked to select a snack product as a compensation for their participation. The experiment was conducted using an eye tracker.

Setting: Montevideo (Uruguay).

Participants: Convenience sample of 201 people (18-51 years old, 58\% female). Results: The average percentage of participants who fixated their gaze on the nutritional warnings during the choice task was slightly but significantly higher for participants who attended to nutrition messages (regardless of their framing) compared with the control group. Participants who attended to loss-framed messages fixated their gaze on the warnings for the longest period of time. In addition, the healthfulness of the snack choices was higher for participants exposed to nutrition-related messages compared with the control group.

Conclusions: Results from the present work suggest that nutrition messages aimed at increasing awareness of nutritional warnings may increase consumers' visual attention and encourage more heathful choices. The framing of the messages only had a minor effect on their efficacy.
\end{abstract}

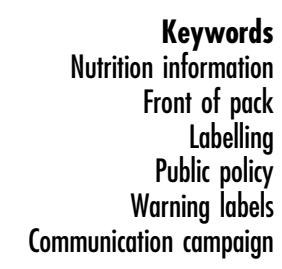

Nutritional warnings have recently been introduced as a front-of-package (FOP) nutrition labelling scheme to facilitate the identification of products with excessive content of nutrients associated with non-communicable diseases ${ }^{(1)}$. This scheme was first implemented in Chile and has recently been adapted by other countries, such as Peru $^{(2)}$, Israel ${ }^{(3)}$ and Uruguay ${ }^{(4)}$. One of the main reasons for the increasing popularity of nutritional warnings is their potential to discourage consumption of non-core food products with high sugar, fat and sodium content ${ }^{(5-7)}$. This is particularly relevant in the Latin American context given the sharp increase in the consumption of ultraprocessed products with unfavourable nutrient profile in the last decade ${ }^{(8,9)}$.
Familiarity with a FOP nutrition labelling scheme has been reported to be one of the main determinants of its efficacy to influence consumer food choices ${ }^{(10-12)}$. This highlights that there is a need to implement communication campaigns that accompany the introduction of FOP nutrition labelling, because this way consumers recognize in-store what they have seen in media and promotional materials. Such accompanying campaigns should make the visual design of the FOP scheme known, explain how it can be used and motivate citizens to take nutrition labelling into account during food purchases.

Effective communication campaigns should include information relevant for the target behaviour that matches people's prevailing concerns ${ }^{(13)}$. In the specific case of 
nutritional warnings, previous research has shown that interest in health is the main motivation underlying consumers' willingness to take them into account while shopping for food ${ }^{(14)}$.

FOP nutrition labels of the variant of nutritional warnings are yet in the introductory stage in many markets. It is therefore important to identify which are the best approaches to introduce them, and how to phrase or frame the benefit of using the warning to consumers. Messages aimed at promoting the use of nutritional warnings should be framed in a manner that maximizes their impact on consumers' behaviour ${ }^{(15)}$. Such messages can emphasize the benefits of engaging in the behaviour (gain frame) or the cost of failing to engage in the behaviour (loss frame) ${ }^{(16)}$. Gain-framed messages intend to elicit positive emotional appeal, whereas loss-framed messages tend to have negative emotional appeal ${ }^{(17)}$. This simple variation in how messages are framed has been reported to impact their efficacy for promoting behaviour change ${ }^{(18)}$.

According to the prospect theory ${ }^{(19)}$, people's decisions regarding prospects of gain and loss under uncertainty are not perfectly rational. Decision making involves a phase of framing and editing in which individuals perform a preliminary analysis of the decision and its associated acts, contingencies and outcomes on the basis of how the choice situation is presented ${ }^{(20)}$. Tversky and Kahnemann have shown that people tend to show an aversion to loss, suggesting that losses are more relevant for decision making than gains ${ }^{(21)}$.

In the context of health-related messages, Rothman and Salovey ${ }^{(22)}$ reported that the effect of framing is moderated by risk perception: loss-framed messages are expected to be more efficient than gain-framed messages for promoting health behaviours that are perceived as minimally risky to perform, whereas the opposite trend is expected for behaviours associated with higher risk. In particular, they reported that loss-framed messages tend to be more efficient for promoting disease detection behaviours, whereas a gain frame seems to be more effective for promoting disease prevention behaviours. However, inconclusive evidence exists regarding which type of message framing is more persuasive ${ }^{(23)}$, particularly in relation to nutritionrelated behaviours ${ }^{(24,25)}$.

In this context, the aim of the present work was to evaluate the impact of message framing on attitudes towards the messages, behavioural intention and actual behaviour, evaluated through visual attention to nutritional warnings and the choice of a snack product during a real choice task. An experimental approach was used to compare visual attention to nutritional warnings and choice of snack products after exposure to three types of messages: nonnutrition-related messages, gain-framed nutrition messanges and loss-framed nutrition messages. Results from the present work were expected to contribute to the development of communication campaigns aimed at promoting the use of FOP nutrition labelling schemes.

\section{Materials and methods}

Nutritional warnings have been recently adopted in Uruguay $^{(4)}$, but not yet implemented in the food market. The study was thus conducted in Montevideo, the capital city of Uruguay, between August and December 2018, before the compulsory implementation of nutritional warnings in the marketplace. Following a between-subjects design, participants were exposed to loss-framed nutrition messages, gain-framed nutrition messages or non-nutrition-related messages (control group). After evaluating the messages, participants were presented with an image featuring eight snack products and were asked to select one as a compensation for their participation. The experiment was conducted using an eye tracker to evaluate participants' visual attention to nutritional warnings during decision making.

\section{Participants}

A convenience sample of 201 people participated in the study. They ranged in age between 18 and 51 years (mean 25.6 (SD 6.4) years) and were $58 \%$ female. Participants were recruited among students and workers of the School of Psychology in Montevideo (Uruguay). Recruitment was conducted on different days of the week and at different times of the day to ensure a diverse sample of participants. During recruitment, participants were approached by one of the researchers, who invited them to participate in a study related to a series of messages. No additional details were provided. All participants reported normal or corrected-to-normal vision and full colour vision. An informed consent form was signed at the beginning of the study.

\section{Stimuli}

A total of six messages were developed for each of the following three categories: non-nutrition-related, gain-framed and loss-framed nutrition messages. Non-nutrition-related messages were related to curious facts (e.g. 'When you sneeze your heart stops one millisecond' or 'Did you know that the tongue is the strongest muscle in the body, in relation to its size?'). Gain-framed messages emphasized the advantages of healthy eating or avoiding foods with excessive content of sugar, fat and sodium, whereas loss-framed messages emphasized the negative health consequences of consuming foods with excessive content of sugar, fat and sodium. The exact wording of the nutrition-related messages can be found in Table 1. All the messages were included on a black background using white letters and were accompanied by a picture related to their content, as exemplified in Fig. 1. In the case of the nutrition-related messages, the expression 'Now you can know what you eat', the logo of the Ministry of Health and the warning signs were also included (Fig. 1(b) and (c)). 


\section{Public Health Nutrition}

Table 1 Wording of the nutrition-related messages with different framing and associated images. The percentage of participants who regarded the messages as positive/negative and the average scores for credibility and willingness to follow the recommendations are also shown

\begin{tabular}{|c|c|c|c|c|c|}
\hline Group & Message & Image & $\begin{array}{c}\text { Percentage of } \\
\text { participants who } \\
\text { regarded the } \\
\text { message as } \\
\text { positive/negative } \\
(\%)\end{array}$ & $\begin{array}{l}\text { Average } \\
\text { credibility score } \\
(1-7)\end{array}$ & $\begin{array}{l}\text { Average willingness } \\
\text { to follow the } \\
\text { recommendation } \\
\text { score }(1-7)\end{array}$ \\
\hline \multirow[t]{6}{*}{ Gain frame } & $\begin{array}{l}\text { 1. Reducing your consumption of sugar, fat } \\
\text { and sodium you can increase your quality } \\
\text { of life and well-being }\end{array}$ & $\begin{array}{l}\text { Family sitting at the table and eating } \\
\text { healthy food }\end{array}$ & $76 / 2$ & $6 \cdot 0$ & $6 \cdot 2$ \\
\hline & 2. You are what you eat & Fruit and vegetables & $67 / 2$ & $5 \cdot 2$ & 5.4 \\
\hline & $\begin{array}{l}\text { 3. Prefer consuming natural foods, without excess } \\
\text { of sugar, sodium and fat }\end{array}$ & Bowl with carrot sticks & $74 / 5$ & $5 \cdot 8$ & $6 \cdot 1$ \\
\hline & $\begin{array}{l}\text { 4. Consuming a balanced diet and avoiding foods } \\
\text { with excess of fat, sodium and sugar you have } \\
\text { more chance of living a healthy adulthood }\end{array}$ & Healthy seniors walking in the park & $73 / 2$ & $5 \cdot 8$ & $6 \cdot 0$ \\
\hline & $\begin{array}{l}\text { 5. Avoiding foods with excess of sodium, fat } \\
\text { and sugar reduces your likelihood of suffering } \\
\text { cardiovascular diseases }\end{array}$ & $\begin{array}{l}\text { Person making a heart with the } \\
\text { hands }\end{array}$ & $82 / 4$ & $5 \cdot 6$ & $5 \cdot 9$ \\
\hline & $\begin{array}{l}\text { 6. Avoiding foods with excess of fat, sodium and } \\
\text { sugar you can have an adequate weight and be } \\
\text { healthier }\end{array}$ & Balance with fruit and a centimetre & $73 / 0$ & $6 \cdot 0$ & $6 \cdot 0$ \\
\hline \multirow[t]{6}{*}{ Loss frame } & $\begin{array}{l}\text { 1. Excessive consumption of sugar, fat and } \\
\text { sodium is associated with cardiovascular } \\
\text { diseases and increase likelihood of early } \\
\text { death }\end{array}$ & Body in the morgue & $33 / 31$ & $5 \cdot 1$ & 5.5 \\
\hline & 2. You are what you eat & Fatty fast food & $28 / 19$ & 4.9 & $5 \cdot 1$ \\
\hline & $\begin{array}{l}\text { 3. Avoid consuming foods with excess of sugar, } \\
\text { sodium and fat }\end{array}$ & French fries in a cigarrete package & $40 / 15$ & $4 \cdot 7$ & $5 \cdot 2$ \\
\hline & $\begin{array}{l}\text { 4. Consuming foods with excess of sodium, sugar } \\
\text { and fat increases your likelihood of suffering } \\
\text { diseases when you are older }\end{array}$ & $\begin{array}{l}\text { Sad senior receiving news from a } \\
\text { doctor }\end{array}$ & $37 / 24$ & $5 \cdot 0$ & $5 \cdot 8$ \\
\hline & $\begin{array}{l}\text { 5. Consuming foods with excess of sodium, } \\
\text { sugar and fat increases your likelihood } \\
\text { of suffering cardiovascular diseases }\end{array}$ & A woman grabbing her chest & $40 / 22$ & $5 \cdot 2$ & $5 \cdot 7$ \\
\hline & $\begin{array}{l}\text { 6. Consuming foods with excess of fat, sugar } \\
\text { and sodium not only increases your likelihood } \\
\text { of being overweight and obese, but also of } \\
\text { suffering their consequences }\end{array}$ & $\begin{array}{l}\text { Drawing of a fat person with fast food } \\
\text { inside }\end{array}$ & $40 / 21$ & $5 \cdot 3$ & $5 \cdot 7$ \\
\hline
\end{tabular}

Participants were a convenience sample of people aged 18-51 years ( $n$ 201, 58\% female) from Montevideo (Uruguay), recruited August-December 2018. 


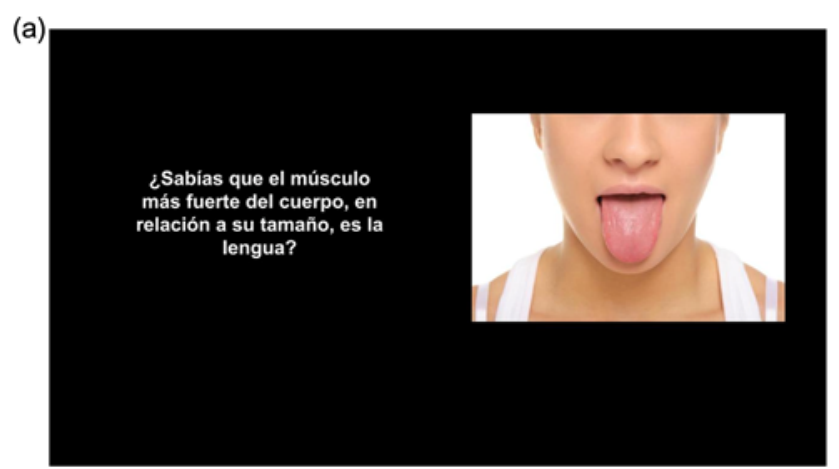

(b)

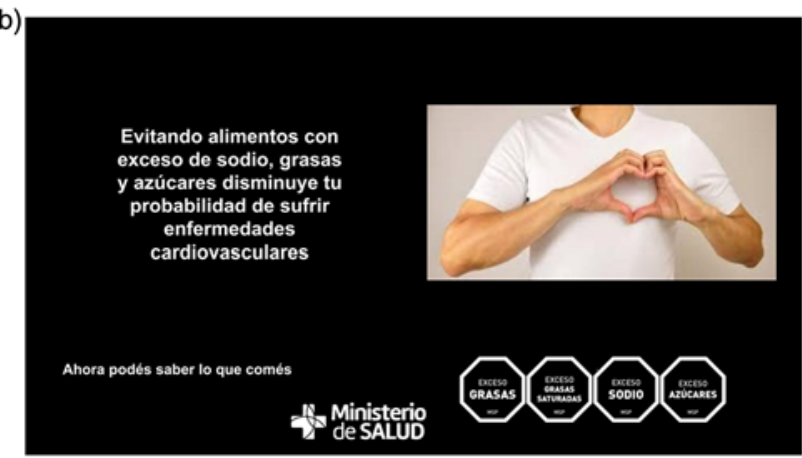

(c)

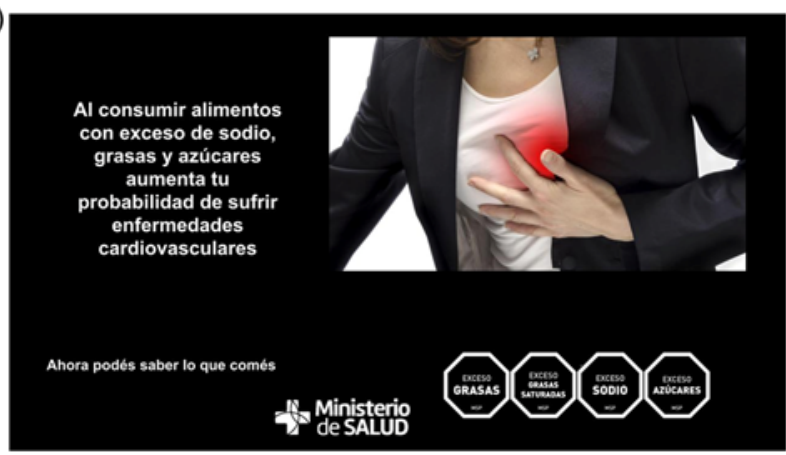

Fig. 1 (colour online) Examples of the messages shown to participants during the first part of the experiment: (a) non-nutritionrelated message; (b) gain-framed message; and (c) loss-framed message

\section{Experimental procedure}

Participants were randomly and unobtrusively divided into three experimental groups involving the three types of messages: non-nutrition-related messages ( $n$ 67), gainframed nutrition messages ( $n$ 67) and loss-framed nutrition messages ( $n$ 67). No significant differences in the age and gender distribution of the groups were found $(P=0.48$ and $P=0.96$, respectively).

The experiment was conduced in the psychophysics laboratory of the School of Psychology. Participants were asked to sit at a distance of approximately $65 \mathrm{~cm}$ from the monitor of a remote T60 Tobii eye tracker (Tobii Technology, Stockholm, Sweden). They were explained that they had to evaluate a series of messages that would be presented in the monitor of the computer. Then, they completed the 5-point calibration procedure of the software (Tobii Studio Professional; Tobii Techonology).
The six messages (different for each experimental group) were presented on the screen, one by one in random order. For each message, participants had to answer three questions: 'How would you classify the message?' ('negative'/'neutral'/'positive'); 'How credible do you think the message is?' $(1=$ 'not credible at all', $7=$ 'very credible'); and 'Would you be willing to follow the recommendation included in the message?' $(1=$ 'definitely not', $4=$ 'maybe yes, maybe not', $7=$ 'definitely yes'). In the case of the non-nutrition-related messages, the last question was replaced by "Would you be willing to share this information with your friends?'

After participants finished the task, they were invited to select a snack as a compensation for their participation. They were shown a picture containing eight snack products, displayed as if they were positioned on a shelf (Fig. 2). The products included the most frequently consumed snack products in the country: apple, two types of cereal bars, chocolate cookies, chocolate chip cookies, peanuts (salted and unsalted) and alfajor (a typical product made of round layers of dough with a sweet filling between them). Participants had to make a mouse click on the product they would like to take. After they made their choice, the product was handed to them and the experimental task was finished. Products of different categories, all widely available in the Uruguayan marketplace and with similar price (between \$US 0.7 and \$US 1.0), were included. The nutritional criteria included in Uruguayan regulations ${ }^{(4)}$ (which had been approved but not yet implemented in the marketplace at the time of the study) were used to determine the nutritional warnings that should be included on each product. Warnings for excessive fat, saturated fat, sugars and sodium content were included. The nutritional composition of the products and their corresponding warning labels are shown in Table 2 . The selected product was given to the participant right after the test and was the only compensation for participation.

\section{Data analysis}

Participants' subjective perception of the messages was evaluated by calculating the frequency of use of the three response options for the multiple-choice question (classification of the messages into positive/neutral/negative) and the average score of the credibility and willingness to follow the recommendation questions. Differences between participants exposed to gain- and loss-framed messages were evaluated using the $\chi^{2}$ test and the $t$ test, respectively.

For the eye-tracking data, the nutritional warnings displayed on the products (cf. Fig. 2) were considered as areas of interest. Fixations on the areas of interest were identified based on the velocity of the directional shifts of the eye, using the eye-tracking software ${ }^{(26)}$. If the velocity of the eye movements was lower than the pre-determined threshold $\left(30^{\circ} \mathrm{s}\right)$, the movement was classified as part of a fixation. On the contrary, if the velocity was higher than 

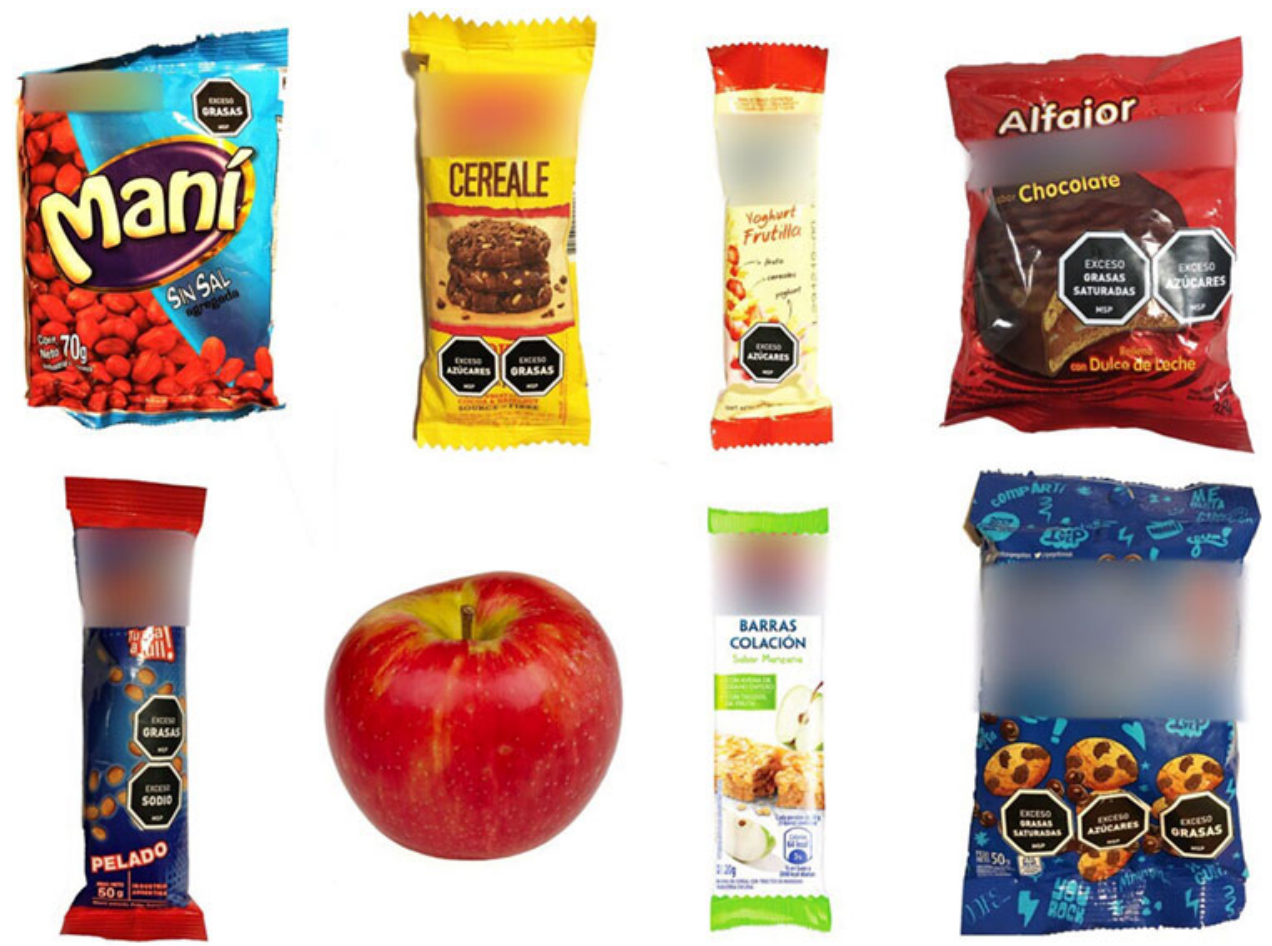

Fig. 2 (colour online) Image featuring snack products from which participants made their choice after the experimental task. Six of the eight products featured nutritional warnings for excessive content of key nutrients (sugars, total fat, saturated fat and/or sodium), as specified in Uruguayan regulations ${ }^{(4)}$. The brands were blinded only for publication but were shown to participants

Table 2 Description of the products included in the shelf, nutritional composition, inclusion of warnings on the packages according to Uruguayan legislation $^{(4)}$ and percentage of participants who selected them in each experimental condition

\begin{tabular}{|c|c|c|c|c|c|c|c|c|c|}
\hline \multirow[b]{2}{*}{ Product } & \multirow[b]{2}{*}{$\begin{array}{c}\text { Energy } \\
\text { content } \\
(\mathrm{kcal} / 100 \mathrm{~g})\end{array}$} & \multirow[b]{2}{*}{$\begin{array}{l}\text { Added } \\
\text { sugars } \\
(\mathrm{g} / 100 \mathrm{~g})\end{array}$} & \multirow[b]{2}{*}{$\begin{array}{c}\text { Total } \\
\text { fat } \\
(\mathrm{g} / 100 \mathrm{~g})\end{array}$} & \multirow[b]{2}{*}{$\begin{array}{c}\text { Saturated } \\
\text { fat } \\
(\mathrm{g} / 100 \mathrm{~g})\end{array}$} & \multirow[b]{2}{*}{$\begin{array}{l}\text { Sodium } \\
(\mathrm{mg} / 100 \mathrm{~g})\end{array}$} & \multirow[b]{2}{*}{$\begin{array}{l}\text { Front-of-pack } \\
\text { warnings }\end{array}$} & \multicolumn{3}{|c|}{$\begin{array}{l}\text { Percentage of participants who } \\
\text { selected the product }(\%)^{*}\end{array}$} \\
\hline & & & & & & & $\begin{array}{l}\text { Control } \\
\text { group } \\
(n 67)\end{array}$ & $\begin{array}{c}\text { Gain-framed } \\
\text { messages } \\
(n 67)\end{array}$ & $\begin{array}{l}\text { Loss-framed } \\
\text { messages } \\
(n 67)\end{array}$ \\
\hline Apple & 63 & 0 & 0 & 0 & 0 & 0 & 30 & 40 & 30 \\
\hline Alfajor & 424 & 39.5 & $14 \cdot 7$ & $7 \cdot 9$ & 161 & $\begin{array}{l}2 \text { (sugar, } \\
\text { saturated } \\
\text { fat) }\end{array}$ & $14(+)$ & 6 & 3 \\
\hline Cereal bar 1 & 421 & $35 \cdot 7$ & $13 \cdot 5$ & 5 & 186 & 1 (sugar) & 9 & 15 & 10 \\
\hline Cereal bar 2 & 320 & $15 \cdot 0$ & 4.0 & 0 & 115 & 0 & 13 & 14 & $25(+)$ \\
\hline $\begin{array}{l}\text { Chocolate } \\
\text { cookies }\end{array}$ & 593 & $40 \cdot 0$ & $25 \cdot 3$ & $4 \cdot 3$ & 433 & $\begin{array}{l}2 \text { (sugars, } \\
\text { total fat) }\end{array}$ & 7 & 4 & 9 \\
\hline $\begin{array}{l}\text { Chocolate chip } \\
\text { cookies }\end{array}$ & 464 & 33.0 & $19 \cdot 0$ & $12 \cdot 0$ & 114 & $\begin{array}{c}3 \text { (sugars, } \\
\text { total fat, } \\
\text { saturated } \\
\text { fat) }\end{array}$ & $15(+)$ & 2 & 3 \\
\hline Salted peanuts & 640 & 0 & $52 \cdot 0$ & 8.4 & 792 & $\begin{array}{l}2 \text { (total fat, } \\
\text { sodium) }\end{array}$ & 4 & 7 & 5 \\
\hline $\begin{array}{l}\text { Unsalted } \\
\text { peanuts }\end{array}$ & 668 & 0 & $52 \cdot 0$ & $2 \cdot 8$ & 7 & 1 (total fat) & 7 & 12 & 15 \\
\hline
\end{tabular}

Participants were a convenience sample of people aged 18-51 years ( $n$ 201, 58\% female) from Montevideo (Uruguay), recruited August-December 2018. To convert to kJ, multiply kcal value by $4 \cdot 184$.

${ }^{*}(+)$ and $(-)$ indicate that the observed value is higher or lower than the expected theoretical value, respectively, according to the $\chi^{2}$ per cell test $(P<0.05)$.

$\dagger$ Alfajor is a typical product made of round layers of dough with a sweet filling between them (usually a type of sweetened condensed milk), covered with chocolate.

the threshold, the movement was classified as part of a saccade. Three eye-tracking measures were calculated using the software: percentage of participants who fixated their gaze on the warnings, fixation count and total fixation duration. These last measures are indicative of the relevance of an area of interest for completing a task ${ }^{(27)}$. The $\chi^{2}$ test was employed to compare the percentage of participants who fixated their gaze on the warnings 
between the three experimental groups. ANOVA was used to establish the existence of significant differences between the mean values of fixation count and total fixation duration between the three groups. Fisher's test was used for post boc comparison of means.

The number of participants who selected each product was determined for each experimental group, as well as the number of participants who selected products featuring nutritional warnings for each of the nutrients. The $\chi^{2}$ test was used to evaluate the existence of significant differences between the experimental groups. The $\chi^{2}$ per cell test was used to identify the source of variation of the global $\chi^{2}$ test.

\section{Results}

\section{Subjective perception of the messages}

As expected, gain- and loss-framed messages were classified differently by participants $(P<0.001)$. On average, $75 \%$ of the participants regarded gain-framed messages as positive (see Table 1 for detailed information), whereas only $3 \%$ regarded them as negative. In the case of lossframed messages, participants tended to give heterogeneous responses. On average, $36 \%$ of the participants regarded these messages as positive, $22 \%$ as negative and the remaining $42 \%$ as neutral.

In general, participants thought that the messages were credible and reported to be willing to follow the recommendations (Table 1). However, significant differences between gain- and loss-framed messages were found. Participants exposed to gain-framed messages gave significantly higher credibility scores than those exposed to lossframed messages $(5.9 v .5 \cdot 5, P<0.001)$ and reported to be significantly more willing to follow the recommendations they included $(5 \cdot 7 v .5 \cdot 0, P<0.001)$.

\section{Choice of snack products}

Significant differences between the three experimental groups were found in the frequency of selection of the snack products $\left(\chi^{2}=25 \cdot 4, P=0 \cdot 031\right)$. As shown in Table 2 , participants in the control group selected alfajor (which featured warnings for sugar and saturated fat) and chocolate chip cookies (which featured warnings for sugar, total and saturated fat) significantly more often than those who attended to gain- or loss-framed nutrition messages. In addition, participants in the loss-framed group selected cereal bar 2 significantly more often than the other two groups. Cereal bar 2 did not feature any warning, whereas cereal bar 1 featured a sugar warning (Table 2). For the rest of the products, differences did not reach significance in the $\chi^{2}$ test.

In terms of the percentage of products featuring nutritional warnings for the different nutrients, significant differences between the experimental groups were found for sugar and saturated fat. Both participants who attended to gain- and those who attended to loss-framed nutrition messages selected products featuring nutritional warnings for sugar significantly less often $\left(\chi^{2}=6.5, P=0.039\right)$ than those in the control group (40 and $66 \%$, respectively). No significant differences between participants who attended to gain- and loss-framed messages were found. The same trend was found for products featuring nutritional warnings for saturated fat $(38,29$ and $86 \%$, respectively; $\left.\chi^{2}=12 \cdot 8, \quad P=0.002\right)$. No significant differences between the groups were found in the percentage of participants selecting products featuring nutritional warnings for total fat $\left(\chi^{2}=0.7, \quad P=0.70\right)$ or sodium $\left(\chi^{2}=1.5\right.$, $P=0 \cdot 48)$.

\section{Visual attention to nutritional warnings during the choice task}

The percentage of participants fixating their gaze on the warnings during the choice task largely differed between products, ranging from 14 to $55 \%$. As shown in Table 3, the average percentage of participants who fixated their gaze on the nutritional warnings was slightly but significantly $\left(\chi^{2}=6.5, P=0.04\right)$ higher for participants who attended to nutrition messages (regardless of the type)

Table 3 Visual attention measures on the nutritional warnings featured on products (cf. Fig. 1) during the choice task of snack products for participants in the three experimental groups

\begin{tabular}{lccc}
\hline & \multicolumn{3}{c}{ Experimental group } \\
\cline { 2 - 4 } & $\begin{array}{c}\text { Control group } \\
(n \text { 67) }\end{array}$ & $\begin{array}{c}\text { Gain-framed } \\
\text { messages } \\
(n 67)\end{array}$ & $\begin{array}{c}\text { Loss-framed } \\
\text { messages } \\
(n \text { 67) }\end{array}$ \\
\hline Eye-tracking measure & $24^{\mathrm{a}}$ & $33^{\mathrm{b}}$ & $33^{\mathrm{b}}$ \\
\hline $\begin{array}{l}\text { Average percentage of participants fixating their } \\
\text { gaze on the warnings (\%) }\end{array}$ & $9-49$ & $18-55$ & $16-61$ \\
$\begin{array}{l}\text { Range of percentage of participants fixating their } \\
\text { gaze on the warnings across products (\%) }\end{array}$ & $2.3^{\mathrm{a}}$ & $1.9^{\mathrm{a}}$ & $2 \cdot 3^{\mathrm{a}}$ \\
$\begin{array}{l}\text { Fixation count on the warnings } \\
\text { Total fixation duration on the warnings (s) }\end{array}$ & $0.31^{\mathrm{a}}$ & $0.31^{\mathrm{a}}$ & $0.43^{\mathrm{b}}$ \\
\hline
\end{tabular}

Participants were a convenience sample of people aged $18-51$ years ( $n 201,58 \%$ female) from Montevideo (Uruguay), recruited AugustDecember 2018

a,bValues within a row with unlike superscript letters were significantly different according to the $\chi^{2}$ per cell test for the percentage of participants who fixated their gaze on the warnings and Fisher's test for the other two measures $(P<0.05)$. 
compared with the control group. The range of percentage of participants fixating their gaze on the warnings across the products also evidenced the difference between the experimental groups (Table 3). The percentage of participants who fixated their gaze on the warrnings varied across products due to differences in their salience owing to their position, size and contrast with the background. Regardless of the experimental condition, the warning displayed on the unsalted peanuts (top left in Fig. 2) was fixated by the lowest percentage of participants: $9 \%$ for the control, $18 \%$ for participants who attended to gain-framed messages and $17 \%$ for participants who attended to lossframed messages. On the contrary, the warnings displayed on the alfajor (top right in Fig. 2) were fixated by the highest percentage of participants: $49 \%$ for the control condition, $55 \%$ for participants who attended to gain-framed messages and $61 \%$ for those who attended to loss-framed messages.

In addition, participants who attended to loss-framed messages fixated their gaze on the warnings for a longer period of time compared with the other two groups $(F=3.87, P=0.02)$. No significant differences between the groups were found in the number of fixations on the warnings $(P=0 \cdot 40)$.

\section{Discussion}

The present study evaluated the influence of framing of nutrition-related messages to promote the use of nutritional warnings during a food choice task. Both gain- and lossframed messages increased participants' attention to the nutritional warnings displayed on food packages during their choice of a snack product compared with the control group exposed to non-nutriton-related messages. These results are consistent with previous studies reporting the value of increasing participants' attention to FOP nutrition labelling through signages in cafeteria or supermarket settings ${ }^{(11,12,28)}$. In addition, exposing participants to nutrition-related messages that raised awareness of the existence of nutritional warnings discouraged the selection of unhealthful snack products, as evidenced by the lower percentage of participants selecting products with warnings for sugar and saturated fat content.

Although nutrition-related messages had a positive effect on visual attention to the warnings and the healthfulness of the snack choices, it should be acknowledged that the study evaluated only their immediate effect. Although signages and promotional materials in-store may contribute to raise awareness of the existence of FOP nutrition labelling on food packages and promote their use, previous studies have shown that actual use of such materials is limited ${ }^{(12)}$. Considering that use of the FOP nutrition labelling is strongly dependent on the salience of the health motive at the point of purchase, multimedia campaigns aimed at increasing health motivation may be more efficient than promotional materials at the point of purchase ${ }^{(12)}$. This stresses the importance of considering multiple campaign elements and communication channels to obtain a cumulative effect ${ }^{(29-31)}$.

Message framing only had a small effect on participants' attitudes, behavioural intention and actual behaviour. Participants regarded gain-framed messages more credible than loss-framed messages and showed a higher intention to follow their recommendations, namely to have a healthy diet and avoid products with excessive content of sugar, fat and sodium. Considering that the behaviours included in the messages can be regarded as disease prevention behaviours, results are in agreement with those reported in the reviews performed by Rothman and Salovey ${ }^{(22)}$ and Gallagher and Updegraff( ${ }^{(16)}$ that concluded that gainframed messages are superior to loss-framed messages. In addition, recent studies have also highlighted advantages of gain-framed messages for promotion of disease prevention behaviours ${ }^{(32-34)}$.

However, a superiority of gain-framed messages on actual behaviour was not observed. During the snack choice task, a slight advantage of loss-framed messages over gain-framed messages was found. Participants exposed to loss-framed messages fixated their gaze for a longer period of time on the nutritional warnings compared with those exposed to gain-framed messages or the control group. This suggests that loss-framed messages were more efficient in encouraging participants to pay attention to the warnings during their decision-making process. In addition, the loss-framed messages induced larger changes in snack selection compared with the gain-framed messages, in particular in terms of the selection of one product (a snack bar without warnings).

Although this result is in agreement with prospect theory ${ }^{(21)}$, it contradicts self-reported data and results from Rothman and Salovey ${ }^{(22)}$. In addition, several published studies evaluating the effect of framing of nutrition messages have reported that there were no significant differences between loss- and gain-framed messages ${ }^{(24,33)}$. Loss-framed messages are usually threatening and can be persuasive, but also lead to defensiveness ${ }^{(35)}$. According to van't Riet et $a l{ }^{(36)}$, the effect of loss-framed messages may depend on how well disposed people are to follow the behaviour. In this sense, it is worth highlighting that Uruguayan consumers have been shown to be positive towards the use of nutritional warnings in decision making $^{(14)}$, as well as to follow the recommendations of the Uruguayan dietary guidelines ${ }^{(37)}$.

The difference between self-reported data and actual behaviour can be attributed to the fact that gain-framed messages were more positive and stressed positive outcomes related to health and well-being, compared with loss-framed messages which stressed negative outcomes related to disease and death. Participants had a more positive attitude towards gain-framed messages, probably because they felt more comfortable with the positive 
outcomes they detailed, compared with messages that emphasized the negative consequences of eating behaviour. However, loss-framed messages were slightly more effective at changing behaviour. This suggests the importance of evaluating the effect of message framing on actual behaviour and not on subjective perception. A previous study with Hispanic participants also reported that although gain-framed messages were more liked than loss-framed messages, the latter were associated with higher behavioural intentions ${ }^{(38)}$.

Finally, it is worth stressing that most of the studies evaluating framing effects have been conducted in Europe or the $\mathrm{USA}^{(16,22)}$. Cultural factors have been reported to play a key role in the effectiveness of health communication and can be mediators of framing effects ${ }^{(39)}$. In particular, differences between individualistic and collectivist cultures have been reported in their reaction to loss- and gain-framed messages. In cultures characterized as individualistic, people are more motivated to pursue opportunities than to avoid making mistakes, focusing on the positive outcomes they hope to approach rather than the negative outcomes they hope to avoid ${ }^{(40-44)}$. Further research studying how culture moderates the framing effects of nutrition-related messages seems necessary.

\section{Limitations of the study}

The present study had several limitations. First of all, it was conducted with a convenience sample of highly educated people given their higher availability to go the the psychophysics laboratory where the eye tracker was located. Although this methodological decision is common practice in studies evaluating framing effects ${ }^{(24,32)}$, it should be acknowledged that results cannot be generalized. In addition, individual differences in how people reacted to message framing were not evaluated. Several personal characteristics have been reported to moderate the effect of framed health messages, including self-efficacy and motivational orientation ${ }^{(32,42,43)}$. Further studies should look into the moderating effect of individual characteristics and personality traits (e.g. temporal orientation) on consumer responses to the framing of nutrition messages aimed at promoting the use of FOP nutrition labelling.

The methodology used to evaluate actual behaviour also had limitations. Although participants took a real product with them, they chose among a limited number of snack products presented in a computer screen, which could have reduced the ecological validity of the choices. Products were presented in the same position for all participants. Although this does not invalidate differences among the experimental conditions, it does not account for spatial preferences during decision making. In addition, the effect of message framing was evaluated immediately after exposure. Previous studies have shown that framing effects are time dependent and can vary largely after exposure ${ }^{(16,31)}$.

\section{Conclusions}

Results from the present work suggest that nutrition messages aimed at increasing awareness of nutritional warnings may increase consumers' visual attention to this FOP nutrition labelling scheme and encourage more heathful choices. This stresses the need to implement multichannel campaigns during the implementation of nutritional warnings in the marketplace. The framing of the messages only had a minor effect on their efficacy. Although participants showed a more positive attitude towards gain-framed messages, loss-framed messages were slightly more efficient than gain-framed messages to increase visual attention to the warnings and led to larger changes in the choice of snacks compared with the control group. The present work showed that public awareness campaigns aimed at promoting healthier dietary patterns could benefit from the use of loss-framed messages, even if people perceive them less positively than gain-framed messages. These results provide additional evidence of the inconclusiveness of framing effects and stress the need to conduct further research to identify the psychological processes that mediate the effects of framing of nutrition-related messages aimed at promoting disease prevention behaviours. Further research is also necessary to provide more in-depth insights for the design of communication campaigns aimed at encouraging the use of FOP nutrition labelling schemes. This holds in particular for participants from cultural backgrounds yet under-represented in the scientific literature.

\section{Acknowledgements}

Financial support: Financial support was obtained from UNICEF Uruguay, Espacio Interdisciplinario (Universidad de la República, Uruguay) and Comisión Sectorial de Investigación Científica (Universidad de la República, Uruguay). The funding organizations were not involved the design/conduct of the study, collection/analysis/ interpretation of the data or preparation/review/approval of the manuscript. Conflict of interest: None. Authorship: All authors contributed to the development of the research. G.V. and L.M. carried out data collection. G.A. and L.M. analysed the data and prepared a first version of the paper, to which all other authors then contributed substantially. Ethics of buman subject participation: This study was conducted according to the guidelines laid down in the Declaration of Helsinki and all procedures involving human subjects were approved by the Ethics Committee of the School of Chemistry of Universidad de la República (Uruguay). Written informed consent was obtained from all participants and formally recorded. 


\section{References}

1. Corvalán C, Reyes M, Garmendia ML et al. (2013) Structural responses to the obesity and non-communicable disease epidemic: the Chilean law of food labelling and advertising. Obes Rev 14, 79-87.

2. Ministerio de Salud de Perú (2018) Manual de Advertencias Publicatarias para el Rotulado Alto en Sodio, Alto en Azúcar, Alto en Grasas Saturadas, o Contiene Grasas Trans. Lima: Peruano.

3. Ministry of Health of Israel (2018) Food label and nutritional labelling. https://www.health.gov.il/English/Topics/Food AndNutrition/Nutrition/Adequate_nutrition/Pages/labeling. aspx (accessed January 2019).

4. Ministerio de Salud Pública (2018) Decreto $N^{\circ} 272 /$ 18.Montevideo: Ministerio de Salud Pública.

5. Khandpur N, Swinburn B \& Monteiro CA (2018) Nutrientbased warning labels may help in the pursuit of healthy diets. Obesity (Silver Spring) 26, 1670-1671.

6. Machín L, Aschemann-Witzel J, Curutchet MR et al. (2018) Does front-of-pack nutrition information improve consumer ability to make healthful choices? Performance of warnings and the traffic light system in a simulated shopping experiment. Appetite 121, 55-62.

7. Ares G, Aschemann-Witzel J, Curutchet MR et al. (2018) Nutritional warnings and product substitution or abandonment: policy implications derived from a repeated purchase simulation. Food Qual Prefer 65, 40-48.

8. Pan American Health Organization (2015) Ultra-Processed Food and Drink Products in Latin America: Trends, Impact on Obesity, Policy Implications. Washington, DC: PAHO.

9. Monteiro CA, Moubarac JC, Cannon G et al. (2013) Ultraprocessed products are becoming dominant in the global food system. Obes Rev 14, 21-28.

10. Cioffi CE, Levitsky DA, Pacanowski CR et al. (2015) A nudge in a healthy direction. The effect of nutrition labels on food purchasing behaviors in university dining facilities. Appetite 92, $7-14$.

11. Graham DJ, Lucas-Thompson RG, Mueller MP et al. (2017) Impact of explained $v$. unexplained front-of-package nutrition labels on parent and child food choices: a randomized trial. Public Health Nutr 20, 774-785.

12. Mørk T, Grunert KG, Fenger M et al. (2017) An analysis of the effects of a campaign supporting use of a health symbol on food sales and shopping behaviour of consumers. BMC Public Health 17, 239.

13. Rimer BK \& Kreuter MW (2006) Advancing tailored health communication: a persuasion \& message effects perspective. J Commun 56, issue S1, S184-S201.

14. Ares G, Aschemann-Witzel J, Curutchet MR et al. (2018) A citizen perspective on nutritional warnings as front-of-pack labels: insights for the design of accompanying policy measures. Public Health Nutr 21, 3450-3461.

15. Rothman RL, Housam R, Weiss H et al. (2006) Patient understanding of food labels: the role of literacy and numeracy. $\mathrm{Am}$ J Prev Med 31, 391-398.

16. Gallagher KM \& Updegraff JA (2012) Health message framing effects on attitudes, intentions, and behavior: a meta-analytic review. Ann Behav Med 43, 101-116.

17. Hale JL \& Dillard JP (1995) Fear appeals in health promotion campaigns: too much, too little, or just right? In Designing Health Messages: Approaches from Communication Theory and Public Health Practice, pp. 65-80 [E Maibach \& RL Parrot, editors]. Thousand Oaks, CA: SAGE Publications, Inc.
18. Rothman AJ \& Salovey P (1997) Shaping perceptions to motivate healthy behavior: the role of message framing. Psychol Bull 121, 3-19.

19. Kahneman D \& Tversky A (1979) Prospect theory: an analysis of decision under risk. Econometrica 47, 263-291.

20. Tversky A \& Kahneman D (1986) Rational choice and the framing of decisions. J Bus 59, 251-278.

21. Tversky A \& Kahneman D (1992) Advances in prospect theory: cumulative representation of uncertainty. J Risk Uncertainty 5, 297-323.

22. Rothman AJ \& Salovey P (1997) Shaping perceptions to motivate healthy behavior: the role of message framing. Psychol Bull 121, 3-19.

23. O'Keefe DJ \& Jensen JD (2006) The advantages of compliance or the disadvantages of non-compliance? A meta-analytic review of the relative persuasive effectiveness of gain-framed and loss-framed messages. In Communication Yearbook, pp. 1-43 [CS Beck, editor]. Mahwah, NJ: Lawrence Erlbaum Associates.

24. Brug J, Ruiter RAC \& van Assema P (2003) The (ir)relevance of framing nutrition education messages. Nutr Health 17, 9-20.

25. Aldridge DK (2006) Message Framing Effects in Nutrition Education. Alexandria, VA: US Department of Agriculture, Food and Nutrition Service.

26. Olsen A (2012) The Tobii I-VT Fixation Filter. Algorithm Description. Stockholm: Tobii Technology.

27. Holmqvist K, Nyström M, Andersson R et al. (2011) Eye Tracking: A Comprehensive Guide to Methods and Measures. Oxford: Oxford University Press.

28. Sonnenberg L, Gelsomin E \& Levy DE (2013) A traffic light food labeling intervention increases consumer awareness of health and healthy choices at the point-of-purchase. Prev Med 57, 253-257.

29. Evans WD (2008) Social marketing campaigns and children's media use. Future Child 18, 181-203.

30. Stead M, Hastings G \& McDermott L (2007) The meaning, effectiveness and future of social marketing. Obes Rev $\mathbf{8}$, 189-193.

31. Andreasen AR (1995) Marketing Social Change: Changing Behavior to Promote Health, Social Development, and the Environment. San Francisco, CA: Jossey-Bass.

32. Godinho CA, Alvarez MJ \& Lima ML (2016) Emphasizing the losses or the gains: comparing situational and individual moderators of framed messages to promote fruit and vegetable intake. Appetite 96, 416-425.

33. Van Assema P, Martens M, Ruiter RA et al. (2001) Framing of nutrition education messages in persuading consumers of the advantages of a healthy diet. J Hum Nutr Diet 14, 435442.

34. Bannon K \& Schwartz MB (2006) Impact of nutrition messages on children's food choice: pilot study. Appetite $\mathbf{4 6}$, 124-129.

35. van't Riet J, Ruiter RAC, Smerecnik C et al. (2010) Examining the influence of self-efficacy on message-framing effects: reducing salt consumption in the general population. Basic Appl Soc Psychol 32, 165-172.

36. van't Riet J, Werrij MQ, Nieuwkamp R et al. (2013) Message frame and self-efficacy influence the persuasiveness of nutrition information in a fast-food restaurant. Food Qual Prefer 29, $1-5$.

37. Machín L, Aschemann-Witzel J, Patiño A et al. (2018) Barriers and facilitators to implementing the Uruguayan dietary guidelines in everyday life: a citizen perspective. Health Educ Behav 45, 511-523. 
38. Wirtz JG \& Kulpavaropas S (2014) The effects of narrative and message framing on engagement and eating intention among a sample of adult hispanics. J Nutr Educ Behav $\mathbf{4 6}$, 396-400.

39. Kreuter MW \& McClure SM (2004) The role of culture in health communication. Annu Rev Public Health 25, 439-455.

40. Sherman DK, Uskul AK \& Updegraff JA (2011) The role of the self in responses to health communications: a cultural perspective. Self Ident 10, 284-294.

41. Uskul AK, Sherman DK \& Fitzgibbon J (2009) The cultural congruency effect: culture, regulatory focus, and the effectiveness of gain- $v$. loss-framed health messages. J Exp Soc Psychol 45 535-541.

42. Mann T, Sherman D \& Updegraff J (2004) Dispositional motivations and message framing: a test of the congruency hypothesis in college students. Health Psychol 23, 330-334.

43. Lee AY, Aaker JL \& Gardner WL (2000) The pleasures and pains of distinct self-construals: the role of interdependence in regulatory focus. J Pers Soc Psychol 78, 1122-1134.

44. Higgins ET (1997) Beyond pleasure and pain. Am Psychol 52, 1280-1300. 